\title{
A COMPARATIVE STUDY OF CORTICAL LAG SCREWS AND MINIPLATES FOR INTERNAL FIXATION OF MANDIBULAR SYMPHYSEAL REGION FRACTURES
}

\author{
Mohamed S. Elhussein ${ }^{\prime}$, Ahmed A. Sharara², Hala R. Ragab ${ }^{3}$
}

\begin{abstract}
INTRODUCTION: The management of facial trauma is one of the most rewarding and demanding aspects of oral and maxillofacial surgery. Being the most prominent mobile bone of the facial skeleton, mandible fracture occurs more frequently than any other fracture.

OBJECTIVES: The aim of this study was to compare the outcomes of treatment by the use of cortical lag screws versus miniplates, in patients who have a fracture in the mandibular symphyseal region.

MATERIALS AND METHODS: The present study was conducted on fourteen patients with age ranged from 19-48 years. The patients had mandibular symphyseal region fractures requiring open reduction and internal fixation. The patients were clinically examined postoperatively by assessment of pain, edema, surgical wound, occlusion, teeth vitality and nerve injury. They also were assessed radiographically using orthopantomogram and cone beam computerized tomography $(\mathrm{CBCT})$ to evaluate the adequacy of reduction, healing progression and bone density of the fractured segments.

CONCLUSIONS: Cortical screw fixation using the lag screw principle offers the advantages of fixation, using minimal hardware, and achieving inter-fragmentary compression, and associated with minimal pain and edema when considering the treatment of linear symphyseal region fractures.

KEY WORDS: Lag screw, Miniplate, Symphyseal, fracture.

1- B.D.S. Faculty of Dentistry, Alfateh University, Lybia

2- Professor of Oral \& Maxillofacial Surgery, Faculty of Dentistry, Alexandria University

3- Assistant Professor of Oral and Maxillofacial Surgery, Faculty of Dentistry, Alexandria University
\end{abstract}

\section{INTRODUCTION}

The mandible is the second most commonly fractured bone of the maxillofacial skeleton because of its position and prominence $(1,2)$. Although there is a wide variance in the reported percentage of fractures of the anterior mandible, aggregate analysis places this at approximately $17 \%$ of all mandibular fractures (3).

Historically the mandible fractures were managed through closed techniques, such as maxillomandibular fixation (MMF), splints, and external fixation, and recently the treatment by use of rigid internal fixation to allow rapid return of function and significantly shorter convalescence (4).

The miniplate osteosynthesis has caused a revolution in mandibular fracture treatment, modern systems provide better handling, higher stability and less pressure on the bone (5). The miniplate is small, easily adaptable, and the monocortical screws allow rapid surgical application (6), and it's useful in treatment of all mandibular fracture except comminuted ones (7).

Lag screw technique was first described by Brons and Boering in 1970 (8) who postulated that lag screw not only immobilizes the fracture fragments but also produces a constant compression of the fracture area. Others have similarly illustrated the versatility of lag screws for mandibular fractures (9).

The anterior mandible, between the two mental foramina, is uniquely suited to the application of lag screw fixation for three reasons, the most important one is the curvature of the anterior mandible, this allows placement of lag screws across the symphysis, from one side to the other, for sagittal fractures, and from anterior to posterior for oblique fractures and those of the anterior body region. The second reason the anterior mandible is well suited to lag screw fixation because of the thickness of the bony cortices, which provide extremely secure fixation when the screws are properly inserted. Finally, there are no anatomic hazards below the apices of the teeth until the mental foramina are encountered, this makes lag screw placement extremely simple, safe and reliable in anterior mandibular fractures (10).

Therefore, the present study was designed to compare the outcomes of treatment by the use of cortical lag screws versus miniplates, in patients who have a fracture in the mandibular symphyseal region.

\section{MATERIALS AND METHODS}

This was a prospective clinical and radiographic study. It received clearance by the institutional ethics committee of the Faculty of Dentistry Alexandria University. It was conducted on patients randomly selected from the Emergency Room of the University Hospital of Alexandria and treated in the operating room of the Oral and Maxillofacial Surgery Department, Faculty of Dentistry, Alexandria University.

\section{Patients}

A sample of fourteen patients who met the inclusion criteria were selected purposefully and a written informed consent obtained before treatment. The patients were divided into two equal groups, each group consisted of seven patients.

\section{Group I:}

All the patients involved in this group were treated with open reduction and direct osteosynthesis using two cortical screws by using of lag screw principle. 


\section{Group II:}

All the patient involved in this group were treated with open reduction and direct osteosynthesis using two miniplates.

\section{The patients were selected on the following basis:}

\section{Inclusion criteria}

Cases with fractures in symphyseal region (symphysis / parasymphysis), isolated or combined with other mandibular fractures.

$\square$ No evidence of local infection.

Adult patients 19-48 years of age.

\section{Exclusion criteria}

Patients who are medically/immunologically compromised.

$\square$ Old fracture.

$\checkmark$ Pathological fracture.

Comminuted fractures.

\section{MATERIALS}

A. Miniplates: (Jeil Medical Corporation Company, Seoul, Korea). With thickness of $1 \mathrm{~mm}$. The screws diameter $2 \mathrm{~mm}$, and lengths 6,8,10.

B. Cortical screws: (O\&M medical $\mathrm{GmbH}$ Eschenweg, germany ). The diameter $2.7 \mathrm{~mm}$ and the length ranged from $18-24 \mathrm{~mm}$.

\section{METHODS}

I) Pre-operative assessment and examination

\section{A. History of the patient}

The pre-operative data was collected and recorded including name, age, gender, occupation, address, onset and etiology of the fracture.

\section{B. Clinical examination \\ Extraoral examination \\ a. Inspection}

To record swelling, ecchymosis, deformity of the bony contour, deviation of the mandible during opening and closing.

\section{b.Palpation}

To detect the site of tenderness, step defects and bony crepitus.

\section{Intraoral examination}

\section{a. Inspection}

To find out ecchymosis and fracture haematoma in the buccal and lingual sulci, step defects in the occlusal plane or any occlusal abnormalities and soft tissue laceration.

\section{b. Palpation}

To detect areas of tenderness and alteration of bony contour, each tooth was examined for mobility and fracture.

\section{Radiographic examination}

Standard orthopantomograms (OPG) were performed for all the cases. (Figures 1,2)

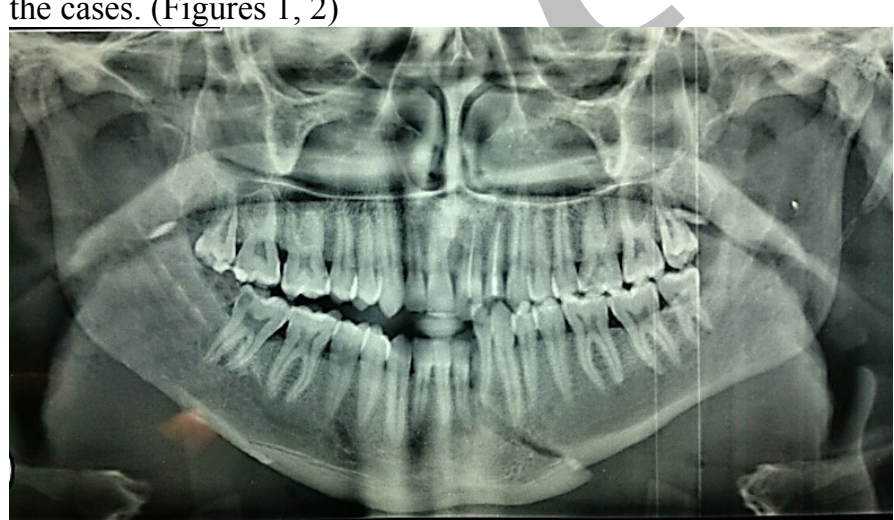

Figure (1): Showing preoperative OPG of lag screws case.

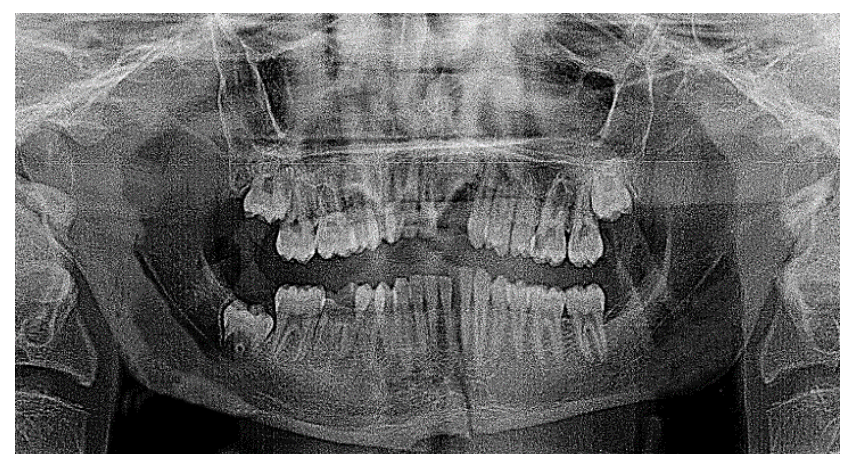

Figure (2): Showing preoperative OPG of miniplates case.

\section{II) Surgical phase}

- General anesthesia was given to all patients.

- The oral cavity was swabbed with povidone iodine solution then all around the extra oral surgical site followed by draping with sterile towels.

- Maxillo-mandibular fixation (MMF) was applied to line up the teeth in normal occlusion.

- The intraoral mandibular vestibular degloving approach being the most preferred approach was used by making a curvilinear incision $3 \mathrm{~mm}$ apical to the mucogingival junction. Exposure of the fracture site was obtained by a standard layered dissection through mucosa, mentalis muscle, and the periosteum. The fragments were reduced and held in apposition and confirmed visually by verifying the alignment of the buccal cortex and inferior border.

For group (A) All the patients involved in this group were treated with open reduction and direct osteosynthesis using two cortical screws. After tracing for lag screw was made, preparation of the pilot and gliding holes, adequate enlargement of the gliding hole using $2.7 \mathrm{~mm}$ diameter drills to prevent thread engagement proximally, and $2.0 \mathrm{~mm}$ diameter drill to thread hole preparation, and preparation of the countersink hole to receive the head of screw. Appropriate length was tightened in the prepared holes and compression of fracture site was achieved by passage of screw through a larger gliding hole to a smaller traction hole on each side of the fracture. Second screw was placed in a similar fashion in the same direction.

For group (B) All the patients involved in this group were treated with open reduction and direct osteosynthesis using two miniplates, were contoured, applied, and fixed using cortical screws, along the line of osteosynthesis. A minimum of two screws were placed on either side of the fracture line for each of the bone plates applied.

Time for hardware application.

The time consumption to install the two lag screws and the two miniplates was calculated.

- Closure of the wound in layers after adequate hemostasis using vicryl suture material (Johnson \& Johnson Int. Eurpean Logistics Centre, Belgium).

- Removal of MMF.

\section{III) Post-operative phase}

- Antibiotics in the form of Amoxicillin $500 \mathrm{mg}+$ Clavulanic acid $125 \mathrm{mg}$ (Augmentin $625 \mathrm{mg}$ manufactured by GlaxoSmithKline) orally three times daily for 5 days.

- Analgesic and anti-inflammatory medication in the form of diclofenac potassium $50 \mathrm{mg}$ tablets (Cataflam50 mg, Novartis company) was given three times daily for five days. 
- Anti-edematous drug in the form of $\alpha$-chymotrypsin ampoules intramuscular injection ( $\alpha$-Chymotrypsin $5 \mathrm{mg}$, Amoun, Egypt) was given once daily for three days.

- Patient instructions: Soft diet for one month, careful oral hygiene.

\section{Follow up phase}

\section{A-Clinical evaluation:}

The patients were assessed at intervals of one, two, four, six and twelve weeks postoperatively for:

a- Pain: It was measured using visual analogue scale. The patients were instructed to draw a vertical line at a point between 0 no pain and 10 unbearable pain (11).

b- Edema: Edema was evaluated by its ability to pit. The examiner fingers were pressed into swelling for 5 seconds. The fingers sank into the swelling and left impression when they were removed. The pitting was graded on scale of +1 to +4 as follows;

+1 (Trace): slight indentation, rapid return to normal.

+2 (Mild): $4 \mathrm{~mm}$ indentation, rebound in few seconds.

+3 (Moderate): $6 \mathrm{~mm}$ indentation, rebound after 10-20 seconds

+4 (Sever): $8 \mathrm{~mm}$ indentation and needs $>30$ seconds to return to normal (12).

c- Surgical wound: The wound was examined for signs and symptoms of infection including redness, swelling, and discharge.

d- State of the occlusion.

e- Condition of the teeth.

f- Nerve function: Assessment of sensory function of the mental nerve was by asking the patient about any alteration in sensation, and using dental probe to assess the sensory changes along the distribution of the mental nerve in comparison to the contra-lateral side.

\section{B- Radiographic evaluation:}

They were followed up radiographically in the immediate postoperative period and after 3 months by orthopantomographs (OPG) and after 6 months by cone beam compute-rized tomography $(\mathrm{CBCT})$. (Figures 3,4$)$

To evaluate:

- Bone density.

- The fracture healing progression.

- The adequacy of reduction of the fractured segments.

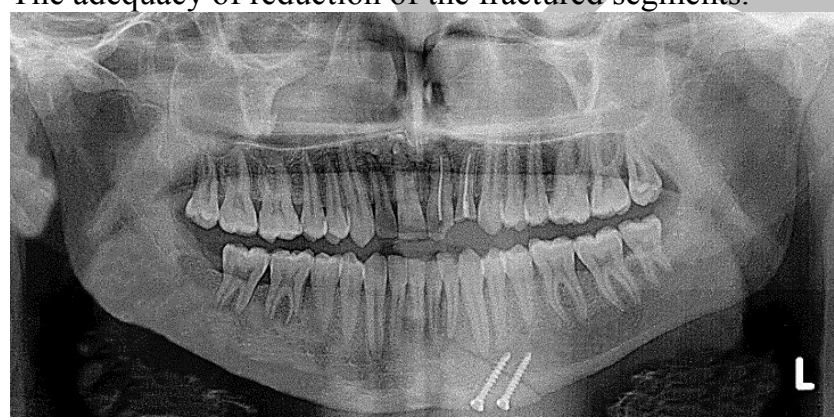

Figure (3): Showing immediate postoperative OPG of lag screws case.

\section{STATISTICAL ANALYSIS}

1 - Student t-test

For normally quantitative variables, to compare between two studied groups

2 - Mann Whitney test

For abnormally quantitative variables, to compare between two studied groups

3 -Wilcoxon signed ranks test
For abnormally quantitative variables, to compare between two periods.

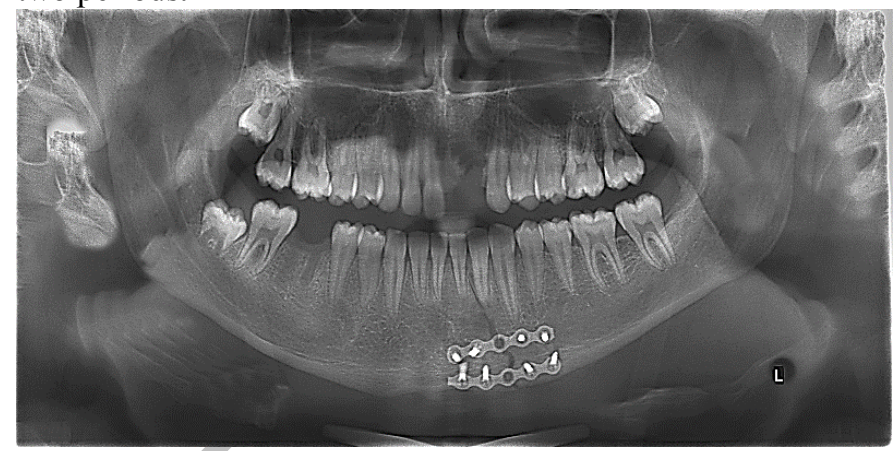

Figure (4): Showing immediate postoperative OPG of miniplates case.

\section{RESULTS}

The study included fourteen patients; eleven males and three females; with a ratio of 3.6:1 Patients' age ranged from (19-48) years old with a mean of $27.14 \pm 4.64$.

The etiological factors of the fractures were $(57.1 \%)$ road traffic accidents (RTA), $(28.6 \%)$ interpersonal violence (IPV) and (14.3\%) fall. (Figure 5)

Distribution of studied cases according to etiology of the fractures $(n=14)$.

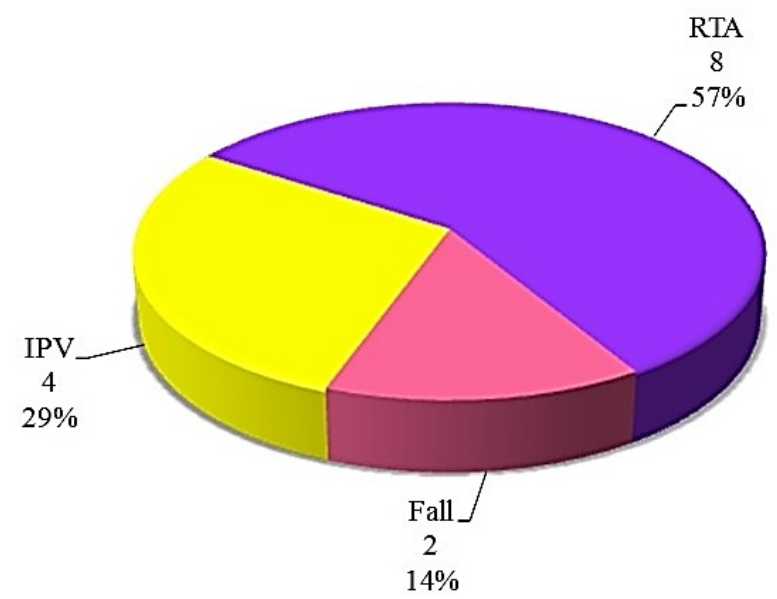

Figure (5): Distribution of studied cases according to etiology of the fractures.

\section{Clinical Data}

\section{I- Preoperative Clinical Data}

Showed tenderness and step deformity, sublingual hematoma, edema and displacement of the fractured segments were observed in all fracture sites, and numbness of the lower lip was observed in 2 cases.

\section{II- Operative Clinical Data}

Time for hardware application: The mean value of the time consumption to install the hardware in study group was $18.57 \pm 1.5$ minutes while in control group was $27.86 \pm 2.1$ minutes which was statistically significant as $\mathrm{p}$ value was $<$ $0.001(\mathrm{P}<0.05)$. (Figure 6)

\section{III- Postoperative Clinical Data}

Immediate postoperative

No complications as bleeding or respiratory obstruction were observed during the first 24 hours. The recovery period was not associated with any complication in all the patients of both groups. 
Comparison between the two studied groups according to time consumption for hardware application

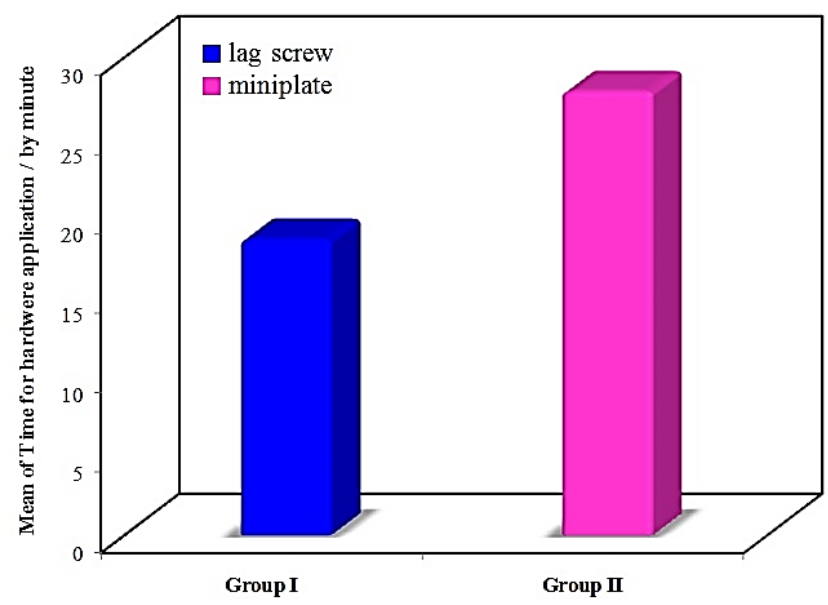

Figure (6): Comparison between the two studied groups according to time consumption for hardware application.

\section{Delayed postoperative}

Every case was monitored for any sign or symptom for 12 weeks postoperatively.

Pain

Pain intensity was decreased in all cases across the follow up period.

After 2 weeks: The mean value of pain score in the study group was $1.57 \pm 0.79$ while in the control group was 2.71 \pm 0.76 which was significant as $\mathrm{p}$ value was $0.023(\mathrm{P}<$ $0.05)$.

The decrease in pain intensity score across follow up period in both groups was statistically significant. (Table 1)

Table (1): Comparison between the two studied groups according to pain.

\begin{tabular}{|c|c|c|c|c|c|}
\hline & One week & 2 weeks & 4 weeks & 6 weeks & 12 weeks \\
\hline \multicolumn{6}{|l|}{ Group I } \\
\hline $\begin{array}{l}\text { Min. - } \\
\text { Max. }\end{array}$ & $3.0-5.0$ & $1.0-3.0$ & $0.0-2.0$ & $0.0-1.0$ & $0.0-0.0$ \\
\hline $\begin{array}{c}\text { Mean. } \pm \\
\text { SD. }\end{array}$ & $\begin{array}{c}3.86 \pm \\
0.69\end{array}$ & $\begin{array}{c}1.57 \pm \\
0.79\end{array}$ & $\begin{array}{c}0.57 \pm \\
0.79\end{array}$ & $\begin{array}{c}0.14 \pm \\
0.38\end{array}$ & $0.0 \pm 0.0$ \\
\hline Median & 4.0 & 1.0 & 0.0 & 0.0 & 0.0 \\
\hline $\mathbf{p}_{1}$ & & $0.014^{*}$ & $0.016^{*}$ & $0.016^{*}$ & $0.016^{*}$ \\
\hline \multicolumn{6}{|l|}{ Group II } \\
\hline $\begin{array}{l}\text { Min. - } \\
\text { Max. }\end{array}$ & $3.0-6.0$ & $2.0-4.0$ & $0.0-2.0$ & $0.0-2.0$ & $0.0-0.0$ \\
\hline $\begin{array}{l}\text { Mean. } \pm \\
\text { SD. }\end{array}$ & $\begin{array}{c}4.43 \pm \\
0.98\end{array}$ & $\begin{array}{c}2.71 \pm \\
0.76\end{array}$ & $\begin{array}{c}0.71 \pm \\
0.76\end{array}$ & $\begin{array}{c}0.43 \pm \\
0.79\end{array}$ & $0.0 \pm 0.0$ \\
\hline Median & 4.0 & 3.0 & 1.0 & 0.0 & 0.0 \\
\hline $\mathbf{p}_{1}$ & & $0.014^{*}$ & $0.016^{*}$ & $0.017^{*}$ & $0.017^{*}$ \\
\hline $\mathbf{Z}(\mathbf{p})$ & $\begin{array}{c}1.172 \\
(0.241)\end{array}$ & $\begin{array}{c}2.274^{*} \\
\left(0.023^{*}\right)\end{array}$ & $\begin{array}{c}0.421 \\
(0.674)\end{array}$ & $\begin{array}{c}0.713 \\
(0.476)\end{array}$ & $\begin{array}{c}0.0 \\
(1.000)\end{array}$ \\
\hline
\end{tabular}

Z: Z for Mann Whitney test for comparing between the two groups $\mathrm{p}: \mathrm{p}$ value for Mann Whitney test for comparing between the two groups $\mathrm{p}_{1}: \mathrm{p}$ value for Wilcoxon signed ranks test for comparing between immediately with after 6 weeks and after 3 months

$*$ : Statistically significant at $\mathrm{p} \leq 0.05$

\section{Postoperative edema/swelling}

Edema was limited to the area of operation. After 2 weeks: In the study group the edema was completely resolved in all the cases while in the control group there was trace edema in (1 case). The edema was resolved completely in all the cases of both groups by end of 4 weeks postoperatively.

\section{Surgical wound:}

Wound healing went uneventful for all cases in which no infection or wound dehiscences were detected.

\section{State of occlusion:}

The examination of occlusion revealed normal occlusion and normal intercuspal relation, there was no need for selective grinding in any case.

\section{Condition of the teeth:}

All teeth remained vital, except in 3 cases due to injury. The non-vital teeth were treated by root canal treatment. (2 cases) in study group and ( 1 case) in control group.

\section{Nerve function:}

Sensory impairment of the lower lip in 2 cases preoperative due to injury, and 3 cases postoperative (1 case) in study group and ( 2 cases) in control group. All cases regain their normal sensation by the end of 12 weeks postoperative follow up.

\section{Radiographic data}

The postoperative OPG was analyzed using Image J. Two points were measured in each OPG, one at the fracture line and the other as reference point at same level in the sound bone to be standardized in the two postoperative OPG views.

The difference in bone density between the point at the fracture line and the reference point represented by the difference in pixel density.

Difference in pixel density was decreased in both groups across the follow up period, and was statistically significant as $\mathrm{p}$ value was $<0.018(\mathrm{p}<0.05)$.

After 12 weeks: The mean difference in pixel density in the study group was $5.14 \pm 1.95$ while in the control group was $14.14 \pm 2.19$ which was statistically significant as $p$ value was $<0.002(\mathrm{p}<0.05)$. (Table 2$)$

After 6 months: The alignment of the fractured segments of both groups was good on cone beam computed tomography (CBCT).

Table (2): Comparison between the two studied groups according to difference in pixel density.

\begin{tabular}{|c|l|l|c|}
\hline & $\begin{array}{c}\text { Difference in } \\
\text { immediate } \\
\text { postoperative }\end{array}$ & $\begin{array}{c}\text { Difference } \\
\text { after 12 } \\
\text { weeks }\end{array}$ & p \\
\hline Group I & $17.0-30.0$ & $3.0-8.0$ & \\
Min. - Max. & $5.14 \pm 1.95$ & $0.018^{*}$ \\
Mean. \pm SD. \\
Median & $22.14 \pm 4.53$ & 5.0 & \\
\hline Group II & 23.0 & $11.0-17.0$ & \\
Min. - Max. & $20.0-31.0$ & $14.14 \pm 2.19$ & $0.018^{*}$ \\
Mean. \pm SD. & $26.0 \pm 3.83$ & 15.0 & \\
Median & 27.0 & $3.137^{*}\left(0.002^{*}\right)$ & \\
\hline $\mathbf{p}_{1}$ & $1.542(0.123)$ & \\
\hline
\end{tabular}

$\mathrm{p}$ : $\mathrm{p}$ value for Wilcoxon signed ranks test for comparing between the two studied groups

$\mathrm{p}_{1}$ : $\mathrm{p}$ value for Mann Whitney test for comparing between after 6 weeks and after 12 weeks

*: Statistically significant at $\mathrm{p} \leq 0.05$

\section{DISCUSSION}

Our study evaluated clinically and radiographically the use of lag screws in comparison to miniplates for symphyseal region fractures. This study was carried out on fourteen patients of both genders. They were treated in Oral and 
Maxillofacial Surgery Department, Faculty of Dentistry, Alexandria University.

In the current study, we were in agreement with most studies about the age distribution (13-15). It is thought that this result is due to the fact that in our country the young adults present a large mass and are the main active segment of population who participate in out-side activities.

About the gender distribution of this study showed that most of the patients were males. The low female incidence in this study could be attributed to the fact that women in our country do not participate in the same physical activities and are less exposed to violence as men are and thus are less exposed to trauma. That was in agreement with Bakardjiev in 2007 (16), and Gutta in 2014 (17) who showed a lower incidence of maxillofacial fractures in women.

About the etiology of mandibular fracture in our study, road traffic accidents were the main etiologic factor. This was found to be in agreement with Brasileiro in 2006 (18), and Bormann et al in 2009 (19). In the developing countries road traffic accidents are responsible for the majority of facial fractures including the mandible because of careless driving manner and bad conditions of both roads and vehicles.

In this study, no postoperative maxillomandibular fixation (MMF) was applied to any of the patients and healing was achieved in all patients. This is consistent with Ellis et al in 1999 recommendations $(20,21)$. This study disagrees with Saad's in 2000 (22) recommendation for the use of postoperative MMF for two weeks for displaced fractures as we obtained proper fracture segments stabilization without the use of MMF. It might be of help in severely comminuted fractures but not simple ones.

In the current study, regarding the time consumption for hardware application was less for study group as compared to control group. That was in agreement with Ellis and Ghali in 1991 (10), and Schaaf et al in 2011 (23) who reported that lag screws could be applied more rapidly as compared to miniplates as the latter require contouring and adaptation.

Regarding the pain, the mean pain score in study group was less than that in the control group in all follow up periods. That was in agreement with Bhatnagar in 2013 (24) who mentioned that pain scores postoperatively were higher in miniplates group than that in lag screws group. Adequate stabilization of the fracture segments eliminated the pain at the fracture site and may be presumed that the greater quantity of implanted hardware and the greater amount of bone drilling required for placement of a large number of screws in the miniplate group contributed to more persistent postoperative pain.

Regarding the edema, less duration post-operative edema was found in the study group as compared to control group. That was in agreement with Agnihotri in 2014 (25) who mentioned that duration of postoperative edema in miniplates group was more than that in lag screws group. It may be presumed that the more time for tissue retraction to install the hardware in control group than in study group and greater quantity of implanted hardware in control group contributed to more persistent postsurgical edema. Within four weeks the edema was completely resolved in all cases of both groups.

In current study, reported temporary sensory impairment was noted to be present in 3 patients postoperatively; (1 case) in study group and ( 2 cases) in control group. Guimond et al in 2005 (26) reported that the most probable reason for intraoperative damage to the nerve is the fracture manipulation, rather than drilling and screws placement close to the nerve. Careful intraoperative identification and preservation of the mental nerve along with gentle retraction to mitigate the possibility of this complication. All cases of current study regain their normal sensation by the end of 12 weeks postoperative follow up.

Regarding the occlusion, the examination of occlusion revealed normal occlusion and normal intercuspal relation so there was no need for selective grinding in any case. That was in agreement with Haranal et al in 2012 (27). Ideal prerequisites to prevent mal-occlusion are stable intraoperative MMF, proper adaptation of plates, drilling holes' perpendicular to the fracture line in the case of lag screws, and verification of accurate anatomic reduction of the lingual cortical plate.

In this study, less difference in pixel density in the lag screws group than that in miniplates group reveal the support effect of lag screws on the bone healing process. That was in agreement with Jadwani in 2011 (28), and other studies $(29,30)$ who mentioned the primary advantage of the lag screws lies in providing compression to the fragments so that primary bone healing can be achieved.

In this study, we were in agreement with Goyal et al in 2012 (31). There is good alignment of the fractured segments of both groups after 6 months postoperative follow up. Cone beam computed tomography (CBCT) images allow to visualize the hardware proximity to the teeth and adjacent vital structures and visualize the site of the fracture without magnification of images. That was in agreement with Suomalainen in 2015 (32), and Heiland in 2004 (33) who mentioned that the CBCT image visualization can give excellent accuracy and without magnification of images.

\section{CONCLUSIONS}

Fixation of symphyseal and parasymphyseal fractures by cortical screws using the lag screw principle achieves good stability. The technique is simple and easily performed, reducing the surgical time, pain and edema, and supporting the healing process in non-comminuted fractures.

\section{CONFLICT OF INTEREST:}

The authors declare that they have no conflicts of interest.

\section{REFERENCES}

1. Ogundara BO, Bonnick A, Bayley N: Pattern of mandibular fractures in an urban major trauma center. J Oral Maxillofac Surg 2003; 61:713

2. Fasola AO, Obiechina AE, Arotiba JT: Incidence and pattern of maxillofacial fractures in the elderly. Int J Oral Maxillofac Surg 2003; 32:206

3. Tiwana PS, Kushner GM, Alpert B. Lag screw fixation of Anteriormandiblular fracture: a retrospective analysis of intraoperative and postoperative complications. J Oral MaxillofacSurg 2007; 65:1180-5

4. Iizuka $T$, Lindqvist $C$. Rigid internal fixation of mandibular fractures. Int J Oral Maxillofac Surg 1992; 21:65-9.

5. Sauerbier S, Schon R, Otten JE, Schmelzeisen R, Gutwald R. The development of plate osteosynthesis for the treatment of fractures of the mandibular body a literature review. J Cranio Maxillofac Surg 2008; 36:251-9. 
6. Szabo G, Kovacs A, Pulay G. Champey's plates in mandibular surgery. Int J Oral Maxillofac Surg 1991; 29:73-4

7. Ikemura K, Kouno Y, Shibita H, Yamasaki k. Biomechanical study on monocortical osteosynthesis for the fracture of the mandible. Int J Oral Surg 1984; 13:2903.

8. Brons R, Boering G. Fractures of mandibular body treated by Stable internal fixation a preliminary report. J Oral Maxillofac Surg 1970; 28:407-15.

9. Niederdellmann H, Schilli W, Duker J, Akuaoma-Boateng E. Osteo- synthesis of mandibular fractures using lag screw. Int J Oral Surg 1996; 5:117-21

10. Ellis III Edward, Ghali GE. Lag screw fixation of anterior mandibular fractures. J Oral Maxillofac Surg 1991; 49:1321

11. Chang JD, Bird SR, Bohidar NR, King T. Analgesic efficacy of rofecoxib compared with codeine/ acetaminophen using a model of acute dental pain. Oral Surg Oral Med Oral Path Oral RadiolEndod 2005; 100:7480 .

12. Wakuloba G, Mahallawy A, Ragab H. Evaluation of dynamic compression miniplates in treatment of mandibular angle fractures using trocar. ADJ 2015;40: 8693.

13. Balasubramanian $S$, Kumaravelu $C$, Elavenil $P$, Krishnakumar Raja V B. Solitary lag-screw fixation for mandibular angle fractures: Prospective study. SRM J Res Dent Sci 2014; 5:180-5

14. Subhashraj K, Ramkumar S, Ravindran C. Pattern of mandibular fractures in Chennai, India. Br J Oral Maxillofac Surg. 2008; 46:126-7

15. Lee T, Sawhney R, Ducic Y. Miniplate fixation of fractures of the symphyseal and parasymphyseal regions of the mandible: a review of 218 patients. JAMA facial plastic surgery 2013; 15:121-25

16. Bakardjiev A, Pechalova P. Maxillofacial fractures in Southern Bulgaria- a retrospective study of 1706 cases. J Cranio Maxillofac Surg 2007; 35:147-50.

17. Gutta R, Tracy K, Johnson C, James LE, Krishnan DG, Marciani RD. Outcomes of mandible fracture treatment at an academic tertiary hospital: a 5-year analysis. J Oral Maxillofac Surg 2014:72:550-8.

18. Brasileiro BF, Passeri LA. Epidemiological analysis of maxillofacial fractures in Brazil: a 5-year prospective study. Oral Surg Oral Med Oral Pathol Oral Radiol Endod 2006; 102:28-34.

19. Bormann KH, Wild S, Gellrich NC, Kokemüller H, Stühmer C, Schmelzeisen R, et al. Five-year retrospective study of mandibular fractures in Freiburg, Germany: incidence, etiology, treatment, and complications. J Oral Maxillofac Surg 2009; 67:1251-5.

20. Ellis E III: Treatment methods for fractures of the mandible angle. Int J Oral Maxillofac Surg 1999; 28:243-52.

21. Potter J, Ellis E 3rd. Treatment of mandible angle fractures with a malleable noncompression miniplate. J Oral Maxillofac Surg 1999; 57:288-92.

22. Saad KA. Evaluation of one non-compression miniplate with or without maxillomandibular fixation for the treatment of mandibular angle fracture. Master Thesis in Oral Surgery. Faculty of Dentistry, Tanta University, 2000.

23. Schaaf H, Kaubruegge S, Streckbein P, Wilbrand JF, Kerkmann H, Howaldt HP. Comparison of miniplate versus lag-screw osteosynthesis for fractures of the mandibular angle. Oral Surg Oral Med Oral Pathol Oral Radiol Endod 2011;111:34-40.

24. Bhatnagar A, Bansal V, Kumar S, Mowar A. Comparative analysis of osteosynthesis of mandibular anterior fractures following open reduction using 'Stainless Steel Lag Screws and Mini Plates. J maxillofac Oral Surg 2013; 12:133-9.

25. Agnihotri A, Prabhu S, Thomas S. A comparative analysis of the efficacy of cortical screws as lag screws and miniplates for internal fixation of mandibular symphyseal region fractures: a randomized prospective study. Int $\mathrm{J}$ Oral Maxillofac Surg 2014;43: 22-8.

26. Guimound C, Johanson JV, Marchena JM. Fixation of mandibular angle fractures with a $2.0 \mathrm{~mm}$ 3-dimentional curved angle strut plate. J Oral Maxillofac Surg 2005; 63:209-14

27. Haranal S R, Neeli A S, Suryavanshi R K, Kotrashetti S M, Naresh N. Titanium lag screw osteosynthesis in the management of mandibular fractures. Int Multidiscip Res J $2012 ; 2: 5-8$

28. Jadwani S, Snehal B. Lag screw fixation of fracture of the anterior mandible: a new minimal access technique. $\mathrm{J}$ Maxillofac Oral Surg 2011; 10:176-180.

29. Lee JK, Angled eccentric osteosynthesis, a new technique for simple mandibular fracture. Surgical Techniques Development 2011; 1:1-2.

30. Grigor'ian AS, Barsegian SN, Laptev PI. Comparative histomorphological analysis of bone fragments consolidation in compression and non-compression mandible osteosynthesis. Stomatologia 2010; 13:89-7.

31. Goyal M, Jhamb A, Chawla S, Marya K, Dua JS, Yadav S. A comparative evaluation of fixation techniques in anterior mandibular fractures using $2.0 \mathrm{~mm}$ monocortical titanium miniplates versus $2.4 \mathrm{~mm}$ cortical titanium lag screws. J Maxillofac Oral Surg 2012;11:442-50

32. Suomalainen A, Esmaeili E P, Robinson S. Dentomaxillofacial imaging with panoramic views and cone beam CT. Insights into imaging 2015;6:1-16.

33. Heiland M, Schulze D, Rother U, Schmelzle R. Postoperative imaging of zygomaticomaxillary complex fractures using digital volume tomography. J Oral Maxillofac Surg 2004; 62:1387-91 